\title{
DA FORÇA SEMPRE ATUAL DO PENSAMENTO DE BENJAMIN CONSTANT E DA NECESSIDADE DE RECONHECÊ-LO
}

\author{
Modesto Florenzano \\ Depto. de História-FFLCH/USP
}

"Defendi por quarenta anos o mesmo princípio, liberdade em tudo, em religião, em filosofia, em literatura, na indústria, na política: e por liberdade entendo o triunfo da individualidade, tanto sobre a autoridade que gostaria de governar despoticamente quanto sobre as massas que reivindicam o direito de dominar a minoria em nome da maioria".
\end{abstract}

E sta passagem, extraída do prefácio que Benjamin Constant escreveu aos seus Mélanges de littérature et de politique, publicados em 1829, um ano antes de sua morte, presta-se admiravelmente para resumir aquele que foi, sem dúvida, o traço mais marcante - e constante - tanto de seu estilo (a um só tempo rico e conciso, eloqüente e lapidar), quanto de sua trajetória: a constância de sua teoria, em meio à inconstância de sua prática. Com efeito, seus escritos muito numerosos (com centenas de textos, longos e curtos, em forma de tratados, artigos, cartas, diário intimo), variados (que vão da literatura - com romance, tragédia e crítica literária à política, passando pela filosofia, história e religião) e repetitivos (daí a dificuldade e uma das razões para a não existência até hoje de suas obras completas), ao mesmo tempo que exprimem o que ele próprio chamou de "uma unidade constante de modo 
de ver", também revelam suas não poucas mudanças de posição e de atitude seja de ordem política, seja de ordem afetiva; algumas até mesmo clamorosas, como as que se deram com Napoleão Bonaparte e com Mme. de Stäel para dar um exemplo de uma e de outra. Daí porque foi apelidado, pelos próprios contemporâneos, de "l'inconstant Benjamin".

Sua consagração e fama, maior no século XIX do que no XX, inclusive no Brasil, deveu-se tanto à política: à sua eloqüente defesa da liberdade; à brilhante e célebre distinção que estabeleceu entre a liberdade dos modernos, que se dá na esfera privada, e a liberdade dos antigos, de participação na vida pública; à sua teoria do poder ou soberania limitada e constitucional; e, entre nós, em particular, a um conceito político, o da necessidade de um poder moderador, ou, nas suas palavras, de um poder neutro ou abstrato; quanto à literatura, mais precisamente a um único romance, Adolphe. Sobre este romance de caráter psicológico (publicado pela primeira vez em 1816, reeditado no mesmo ano, e em terceira edição em 1824), considerado um dos primeiros nesse gênero, já foi observado que ele contém de maneira exemplar tudo o que o autor tinha a dizer como romancista. Em outras palavras, que, se há autores que precisam de muitas obras para expressar toda sua arte, há outros, como Benjamin Constant, para os quais uma única obra é mais do que suficiente. Adolphe expressa de maneira aguda, e foi o primeiro a fazê-lo em termos de novela, a condição da modernidade, o mal-estar inescapável de sermos homens (e mulheres) divididos e românticos, como demonstram as seguintes passagens:

\footnotetext{
"Quase sempre, para estarmos bem interiormente, travestimos nossa impotência e nossa fraqueza em cálculos e sistemas: isto satisfaz a porção de nós que é, por assim dizer, espectadora da outra".

"Estaria equivocado o autor de um ou outro julgamento: não há absolutamente uma unidade completa no homem e quase nunca alguém pode ser totalmente sincero ou totalmente doloso".

"A sociedade me incomoda, a solidão me oprime".

"O amor supre a falta de lembranças por uma espécie de mágica. Todas as outras afeições necessitam de um passado: o amor cria, como por encanto, um passado de que nos cerca. Dá-nos, por assim dizer, a consciência de havermos vivido anos
} 
a fio com alguém que há pouco era quase um estranho. O amor é só um ponto luminoso, e, contudo, parece apoderar-se do tempo. Há poucos dias não existia, logo mais, deixará de existir: mas enquanto existe esparge sua claridade sobre o tempo precedente e sobre o tempo que o sucederá" (Constant 1992: 36, 48 e 47).

De acordo com Pierre Manent, com Constant "a crítica rousseauísta do homem ou da alma moderna coloca-se a serviço do liberalismo"; Constant "voltava sua ironia contra si mesmo e observava que, se seus adversários reacionários ou revolucionários eram insinceros e divididos em sua política, ele, por sua vez, era insincero em seus amores, inseguro e dividido em sua religião íntima. Esse vaivém guiado pela ironia entre a vida pública, onde eram pronunciados discursos retumbantes em favor da liberdade, e a vida privada, onde eram redigidos romances autobiográficos saturados de amargura, resume o 'romantismo' de Benjamin Constant”. Para fundamentar sua brilhante interpretação de que a grande originalidade e contribuição da análise constantiana reside na idéia do anacronismo que domina a vida do homem moderno, Manent cita a seguinte passagem da obra De l'Esprit de Conquête et de l'Usurpation, de 1814,

“...os antigos estavam em plena juventude da vida moral; nós estamos na maturidade, ou talvez na velhice; estamos sempre arrastando conosco não sei que pensamento oculto que nasce da experiência e desfaz o entusiasmo. A condição primordial do entusiasmo é não observar a si mesmo com esmero. Pois bem, temos tanto medo de ser tolos, e sobretudo de parece-lo, que nos observamos incessantemente em nossas sensações mais violentas. Os antigos tinham sobre todas as coisas uma convicção íntegra; nós não temos sobre praticamente coisa alguma mais do que uma convicção frouxa e oscilante, e com essa incompletude em vão procuramos nos aturdir. A palavra ilusão não é encontrada em nenhuma língua antiga, porque a palavra só é criada quando a coisa não existe mais." (Constant, apud Manent 1990: 137 e 139).

A interpretação sugerida por Manent, ilumina um aspecto, uma dimensão bastante original e criativa de Constant, presente tanto em seu romance como em alguns dos seus escritos políticos: a de um pensador tomado de ceticismo e de ironia, ao mesmo tempo seguidor e crítico de Montesquieu e de Rousseau, seguidor e crítico da modernidade. Mas, se tomarmos outros escritos, como, por exemplo, o ensaio 
De la perfectibilité de l'espèce humaine (já pronto em 1805 mas somente publicado em 1829, nos Mélanges de littérature et de politique), veremos que há também um outro Constant, igualmente original e criativo, iluminista mesmo depois da Revolução francesa, pois podemos fazer suas as frases de Mme. de Stäel, escritas em 1799-1800, "São os filósofos que fizeram a Revolução, são eles que irão terminála". "Crê-se sempre que são as luzes que fazem o mal, e quer-se repará-lo fazendo retroceder a razão. O mal das luzes não pode ser corrigido senão adquirindo-se mais luzes ainda". (apud Starobinski 1989: 192). Um Constant embebido de certezas e de otimismo e anunciador de Marx e Comte, de um lado, e Tocqueville, de outro, como demonstram as seguintes passagens:

“(...) Pode-se, tomando épocas da história afastadas uma da outra, mostrar a marcha da perfectibilidade exterior e interior. Por perfectibilidade interior, ou seja, a moral, temos a abolição da escravidão, que é para nós uma verdade evidente, e que era o contrário para Aristóteles.

Na luta da Revolução francesa, os aristocratas mais inveterados não pensaram em propor o restabelecimento da escravidão, e Platão, em sua república ideal, não supõe que se possa dela prescindir.

(...) Por perfectibilidade exterior, temos uma multidão de descobertas: as de Galileu, de Copérnico, de Newton: a circulação do sangue, a eletricidade e um grande número de máquinas que tornam o homem a cada dia mais senhor do universo material; a pólvora, a bússola, a imprensa, o vapor, meios físicos para a conquista do mundo.

(...) Os que não querem reconhecer essa marcha progressiva supõem que a espécie humana está condenada a descrever perpetuamente um círculo, e, por uma alternativa eterna, a passar sem cessar da ignorância às luzes e das luzes à ignorância, do estado selvagem ao estado civilizado e do estado civilizado ao estado selvagem. É que eles se detém sobre algumas porções da terra, sobre algumas sociedades mais ou menos fechadas, sobre alguns indivíduos notáveis ou em seu século ou em sua pátria. Mas para apreciar o sistema da perfectibilidade, não se deve julgá-lo parcialmente. Pouco importa que tal povoação, em tal época, tenha usufruído de mais felicidade ou possuído mais luzes que tal outra, em uma época subsequiente, se está demonstrado que a massa dos homens coexistindo em um tempo qualquer é sempre mais feliz que a massa dos homens coexistindo em um tempo anterior. 
(...) A história nos mostra o estabelecimento da religião cristã e a irrupção dos bárbaros do norte, como as causas da destruição da escravidão; as cruzadas como as da destruição da feudalidade; a Revolução francesa, como as da destruição dos privilégios da nobreza.

Mas essas destruições particulares não foram em absoluto o efeito acidental de circunstâncias particulares; a invasão dos bárbaros, o estabelecimento do cristianismo, as cruzadas, a Revolução francesa foram a ocasião, mas não a causa. A espécie humana estava madura para essas libertações sucessivas. A força eterna das coisas conduz as revoluções em seu movimento. Aquilo que nós tomamos por efeito imediato de uma circunstância imprevista é uma era do espírito humano, e o homem ou o acontecimento que parece tê-lo causado não fez mais do que partilhar mais ostensivamente do impulso geral imprimido a todos os seres. Essas quatro revoluções, a destruição da escravidão teocrática, da escravidão civil, da feudalidade, da nobreza privilegiada, são outros tantos passos em direção ao restabelecimento da igualdade natural. A perfectibilidade da espécie humana não é outra coisa que a tendência em direção à igualdade.

Esta tendência provém de que só a igualdade está em conformidade com a verdade, vale dizer, com as relações das coisas entre si e dos homens entre si.

(...) É preciso uma certa massa de opiniões e de idéias para por em ação as forças físicas, que não são mais que instrumentos passivos. Somente as idéias são ativas; elas são as soberanas do mundo; o império do universo a elas foi dado...

(...) É incontestável que a maioria da raça humana, por uma progressão regular e não interrompida, melhora a cada dia em felicidade e sobretudo em luzes. Ela avança sempre a um passo mais ou menos rápido...'(Constant, apud Gauchet 1997: 709-716).

A contribuição de Constant à política em geral, e ao liberalismo em particular, deveria ser considerada tão importante quanto a dos outros dois gigantes do pensamento francês, Montesquieu e Tocqueville. Apesar de Constant não ter produzido uma obra prima como Do Espírito das Leis, no caso do primeiro, e como A Democracia na América e $O$ Antigo Regime e a Revolução, no caso do segundo, produziu sobre a política (teórica e prática) uma quantidade e qualidade de reflexão de grandeza igual à dos outros dois. De acordo com Marcel Gauchet, Constant deve ser reconhecido como "o teórico dos anos obscuros, como um dos autores que mais 
profundamente tirou a lição do fracasso da Revolução em se estabilizar em uma forma política sólida, como um dos pensadores mais agudos da transição democrática... o homem que se esforçou como nenhum outro em definir a especificidade da 'liberté chez les Modernes' e que, procurando no papel a resposta à questão decisiva sobre a qual tropeçou a vontade revolucionária - o que supõe em matéria de organização do poder a aplicação do princípio representativo - soube, felicidade excepcional, antecipar o movimento histórico real" (Gauchet 1997:19-20).

Constant, foi um analista privilegiado e original das linhas de força da história de seu tempo, vale dizer da Revolução francesa e seus desdobramentos (a era napoleônica e a Restauração) porque, entre outras coisas, sua grande inteligência e capacidade intelectual, a exemplo do que ocorrerá com Marx um pouco mais tarde, foi formada e alimentada pelas três mais importantes vertentes da cultura iluminista européia: a (política) francesa, a (economia) escocesa e a (filosofia) alemã.

Em Benjamin Henri Constant de Rebecque, um horizonte internacional sempre esteve presente, a começar do berço. Nascido em Lausanne, na Suíça, em 1767, de pais huguenotes, de origem francesa, Constant só conseguiu a cidadania francesa, em definitivo, em 1824, depois de muitas solicitações, pois, pelo fato de seus antepassados terem deixado a França antes de Luís XIV expulsar os protestantes com a revogação do Edito de Nantes, não pôde se beneficiar do decreto da Constituinte que dava a nacionalidade aos "fugitivos" daquela revogação.

Acompanhemos brevemente sua vida, sobretudo até 1794-6, quando começa seu envolvimento com Mme. de Stäel e com a Revolução francesa e, em função de ambos, sua carreira política, ao mesmo tempo de pensador e de militante. Órfão de mãe, que morre logo depois de seu nascimento, Constant foi educado dentro da cultura francesa, mas por vários tutores, em vários países (além da Suíça, os Países Baixos) e universidades (na Alemanha e na Escócia - em Edimburgo - onde termina seus estudos em 1783-85). Depois de formado, viaja pelos Países Baixos, Inglaterra e França (onde passa duas temporadas em Paris, 1785 e 1786-7), mas é na Alemanha que começa sua vida profissional, em 1788, ao se empregar como kamarling na corte do duque de Brunswick, onde permanece até 1794. 
A partir de 1789, acompanha atentamente o desenrolar da Revolução francesa, e, por sua correspondência, sabe-se: de seu entusiasmo com a abolição dos privilégios; de sua leitura e crítica ao livro de Burke; de sua simpatia pelos girondinos, de sua alegria com a vitória francesa em Valmy, em 1792, (apesar de - ou talvez mais ainda por causa de - ser o duque de Brunswick, seu patrão, o comandante das tropas aliadas contra a França revolucionária); o terror e os seus desdobramentos o deixam preocupado e desgostoso mas não ao ponto, como ocorrerá com muitos, de fazê-lo descrer e renegar a revolução. Em setembro de 1794, trava conhecimento com Germaine Necker, a filha do célebre financista e ministro, então já Mme. de Stäel, cujo projetos coincidem com os seus. Ela quer voltar à França para aí atuar politicamente ("no sublime teatro da ambição republicana"), mas para isso precisa de um porta-voz masculino; ele quer precisamente a mesma coisa, mas precisa de um patrocinador. Em maio de 1795, pouco depois da Convenção ter esmagado a última tentativa dos sans-culottes e jacobinos derrubarem a política posta em prática pelos termidorianos, Mme. de Stäel reabre seu salão em Paris e Constant é seu freqüentador mais assíduo.

Em 1798, já conhecido graças ao sucesso obtido com De la force du gouvernement actuel de la France et de la nécessité de s'y rallier (e com Des réactions politiques e Des effects de la Terreur) e com todos os seus bens transferidos e investidos em solo francês, consegue tornar-se cidadão desse país; mas não consegue se eleger deputado. De 1799 até 1802, é membro do Tribunat instituído pelo consulado de Napoleão Bonaparte. Depois de romper com este, viaja com Mme. de Stäel para a Alemanha onde encontra Goethe e Schiller. Por volta de 1806, sem deixar de ser liberal, ou melhor, precisamente para se tornar um liberal, deixa de ser republicano e torna-se adepto e defensor da monarquia constitucional, dissociando, nas palavras de Gauchet, a questão da forma do governo da questão dos princípios da liberdade política, pois, para Constant, estes últimos são "compatíveis com a realeza tanto quanto com a república" (Gauchet 1989: 159). Em 1811, depois de uma relação de 17 anos, rompe definitivamente com Mme. de Stäel. Em 1814-5, torna-se, no governo dos cem Dias, Conselheiro de Estado de Napoleão, com o qual tem várias audiências. 
A partir de 1814, escreve sobre constitucionalismo e religião e publica artigos em jornais; em 1818-20, sai o Cours de Politique Constitucionelle (4 volumes); em 182022, Mémoires sur les Cent-Jours (em duas partes). Em 1819, elege-se deputado (não consegue se reeleger dois anos depois, mas o faz em 1824, em 1827 e 1830) e, em 1821, pronuncia discursos contra o tráfico de escravos. Em 1827, sai o primeiro dos cinco volumes da obra De la religion considérée dans sa source.... Em 1928, fracassa em sua última tentativa para entrar na Académie de France, mas em 1830, entre tantos reconhecimentos oficiais (seu enterro, em Paris, no cemitério Père-Lachaise, com cerimonial oficial, foi acompanhado por milhares de pessoas), recebe do novo rei 200.000 francos que lhe permitiram morrer sem dívidas, contraídas ao longo de uma vida também marcada pelo jogo e pela especulação, pelas amantes e por duelos.

\section{III}

Da força do governo atual da França e da necessidade de apoiá-lo, Das reações políticas e Dos efeitos do Terror, os três textos de Constant que aqui se publicam pela primeira vez em tradução portuguesa (sendo que o segundo e o terceiro sairão no próximo número da Revista de História), ocupam um lugar estratégico seja na história pessoal do autor seja na historiografia da Revolução Francesa. Senão vejamos. Em 12 de floréal ano IV ( $1^{\circ}$ de maio de 1796), o Diretório fazia reproduzir no Moniteur, órgão do governo, o panfleto de Constant, Da força do governo atual da França e da necessidade de apoiá-lo, precedido da seguinte apresentação: "Este é o título de uma brochura impressa na Suíça e ainda muito rara na França. É notável ver um estrangeiro discutir com uma sagacidade profunda interesses de nosso país, testemunhar o poderio de nosso governo, demonstrar a fraqueza e os falsos cálculos de seus inimigos, juntando, não sem nuanças, brilho e vigor de estilo à precisão da exposição. Como nós não temos nem o talento nem a pretensão de fazer um livro à respeito do livro; como este que anunciamos pode ser de grande utilidade para o repouso e a felicidade da pátria, acreditamos ser nosso dever torná-lo conhecido por inteiro. Felizes de poder espalhar verdades, não iremos escrutar nem as intenções nem o objetivo do autor; acreditamos que eles sejam louváveis, sinceros e ditados 
pela razão e pela filantropia; este motivo é para nós suficiente para decidir por sua publicação."

Não deixa de ser curioso notar que tanto o escrito de Constant, quanto - justificando sua divulgação - a nota do Moniteur, embora nascidos como textos de intervenção, como armas discursivas visando produzir ação política, foram capazes de elevar-se acima das circunstâncias, dos motivos instrumentais de sua elaboração; o primeiro por articular fato histórico com teoria, interesses com princípios (por reunir, como dirá o próprio Constant, em 1818, ao se referir a esse seu texto, “todos os raciocínios que podem fazer preferir a república à monarquia”), e o segundo, por ter podido ressaltar as verdades e virtudes contidas no panfleto já que estas, ao defenderem a República e a Revolução, mas não o Terror, coincidiam com o desejo do Diretório de consolidar-se no poder. Como quer que seja, ambos, Constant e governo conseguiram o que pretendiam: que o texto fosse amplamente lido, que servisse à defesa do regime revolucionário e republicano, e, ça va sans dire, que trouxesse reconhecimento intelectual ao autor.

Os ataques a Da força do governo atual da França e da necessidade de apoiálo, todos provenientes da direita, tanto da moderada, quanto da radical, ou contrarevolucionária, atestam o sucesso do panfleto e a consagração do autor como publicista. Às fileiras da direita moderada pertencia Adrien de Lezay-Marnesia (1769-1814), cuja crítica ao texto de Constant, aparecia, no mesmo ano IV do calendário revolucionário, em um pequeno panfleto ironicamente intitulado De la faiblesse d'un gouvernement qui commence, et de la nécessité où il est de se rallier à la majorité nationale [Da fraqueza de um governo que começa e da necessidade em que se encontra de se juntar à maioria nacional]. Como fica evidente pelo título do panfleto, para Lezay-Marnesia, ao invés de ser a direita moderada a apoiar o centro, isto é, o governo do Diretório, como quer Constant, é este que, por ser minoritário e fraco, deve apoiar a direita moderada que forma a majorité nationale, portanto, o poder legítimo. Ocorre que, essa última era realista... e, como bem demonstra Constant, no texto em questão, uma volta à monarquia naquele momento, ainda que constitucional, abriria as portas para a contra-revolução e com esta ou à 
vitória dos reacionários e o retorno do absolutismo e do antigo regime ou à vitória dos jacobinos e o retorno do Terror e da Anarquia (isto é, da Democracia)...

“Aqueles que querem derrubar a República são curiosamente vítimas das palavras. Viram que uma Revolução foi uma coisa terrível e funesta, e concluem que o que chamam uma contra-revolução seria um evento feliz. Não se dão conta de que essa contra-revolução apenas seria ela mesma uma nova revolução", afirma Constant em Da força do governo atual da França e da necessidade de apoiá-lo. Não é verdade, responde o reacionário Joseph de Maistre ("o restabelecimento da Monarquia, que chamamos contra-revolução, não será absolutamente uma revolução contrária, mas o contrário da revolução”), em suas famosas Considérations sur la France, publicadas em 1797.

Está claro, para além do jogo de palavras, o que separa de Maistre de Constant e também de Lezay-Marnesia: aquele quer anular a Revolução, estes querem terminála. Os três acabaram vencidos pela história: o primeiro porque "o contrário da revolução" nunca teve lugar na França depois de 1789, e os dois últimos porque a Revolução francesa só terminou, em termos institucionais, com a $3^{\mathrm{a}}$ República, depois de 1870 ... Como bem apontou Philippe Raynaud, em seu prefácio aos três textos de Constant, enquanto este "apostava na 'força' do governo do Diretório, porque considerava que somente ele podia manter as conquistas da Revolução sem recair nos procedimentos de 1793; Lezay considerava-o ao contrário essencialmente fraco porque incapaz de se apoiar nas forças sociais que, somente elas, teriam podido salvá-lo: os golpes de Estado do 18 fructidor e depois do 18 brumário iriam de certa maneira dar razão aos dois" (Reynaud 1988: 17).

Constant respondeu à crítica de Lezay-Marnesia com o panfleto Das reações políticas, de 1797; este, por sua vez, publica, no mesmo ano, Des causes de la Révolution et de ses résultats, e aquele responde com Dos efeitos do Terror. Como se vê, Da força do governo atual da França e da necessidade de apoiá-lo, a primeira publicação de Constant, deu origem a um debate sobre a Revolução francesa, o primeiro - mas o único ocorrido, na França, ainda durante o período revolucionário - de uma série de polêmicas que iriam ter lugar nos dois séculos seguintes. 
Esses três textos de Constant (juntamente com os de Mme de Stäel produzidos na mesma década, os quais, por causa da intimidade existente entre os dois, podem ser considerados como tendo sido escritos a quatro mãos), contém sua interpretação e teoria do fenômeno revolucionário que permanecerão inalteradas até sua morte. Com a primeira (a interpretação), Constant formulou a distinção entre uma Revolução historicamente necessária e benéfica, a Revolução da liberdade de 1789, e uma Revolução historicamente desnecessária e maléfica, a Revolução da igualdade (responsável pelo despotismo e pelo terror) de 1792; e com a segunda (a teoria), a idéia de que o terror deveu-se muito menos às circunstâncias e a uma necessidade histórica irresistível e muito mais ao anacronismo perseguido pelos jacobinos, e do qual eles não eram conscientes, de querem ressuscitar e impor a liberdade antiga ao mundo moderno.

Para provar o valor e a atualidade da interpretação e teoria elaboradas por Constant nesses três panfletos - verdadeiras pedras de toque das vertentes da historiografia liberal de todas as épocas - e, ao mesmo tempo, o pouco reconhecimento de sua contribuição intelectual, basta lembrar, entre outras coisas, que, ambas estão presentes, e ocupando um lugar central, em duas obras muito conhecidas de François Furet. Uma, de 1965, escrita em parceria com Denis Richet, La Révolution Française, responsável pelo início da fama de Furet como historiador revisionista; outra, de 1978, Penser la Révolution Française, responsável pela sua consagração como o maior expoente do revisionismo. Com efeito, tanto a tese sobre a "derrapagem da Revolução", apresentada em 1965, quanto a de que não foram as circunstâncias que criaram o terror mas o terror que criou as circunstâncias, pois este é parte constitutiva e integrante da própria mentalidade revolucionária, apresentada em 1978, nada mais são do que (re)atualizações de idéias formuladas, com muita clareza e acuidade, por Constant, no biênio 1796-97, como o leitor poderá conferir ao ler os panfletos. O mesmo, mutatis mutandis, poder-se-ia dizer da presença de Constant na obra de Tocqueville.

E no entanto, ambos, Tocqueville, primeiro (e até o fim), e Furet, depois (pelo menos até o final da década de 1970, quando, a partir de então, passa a reconsiderar 
a importância de Constant, bem como a de Quinet e Michelet), por motivos que não cabe aqui aventar, esqueceram-se completamente de reconhecer sua dívida para com Constant. Contribuíram, assim, mesmo que involuntariamente, para que, na França, seu nome ficasse muito mal reconhecido, como se pode ver, para dar um exemplo, pelo que se diz no final do verbete Benjamin Constant em um dicionário da Revolução francesa publicado no contexto do bicentenário: "Se ele passou à posteridade, é por causa de seu romance Adolphe, em que aparece bem a indecisão e a ambigüidade de sua personalidade" (Tulard, et alii, 1987). Sobre o lugar de Constant na historiografia da Revolução francesa nem uma única palavra!

Contudo, e fora da França, sempre houve quem soubesse ler e aprender com e dar o devido reconhecimento a - Benjamin Constant. Como foi o caso de Benedetto Croce, Guido de Ruggiero e Norberto Bobbio, na Itália, e, na Inglaterra, de Isaiah Berlin, que, em uma carta a um admirador e estudioso de Burke, pondera: “...você não acha que Benjamin Constant foi, talvez, quem mais agudamente penetrou dentro da Revolução francesa e suas conseqüências? Aquele frio, consciente e independente, civilizado suíço escreveu melhor do que ninguém sobre a destruição da liberdade individual e os horrores tanto do Terror, quanto, de alguma maneira, do regime bonapartista. Não nego que seu famoso ensaio sobre a diferença entre as concepções de liberdade dos mundos antigo e moderno tenha sido uma atraente e forte influência sobre mim. Você conhece seus escritos? Em certos sentidos eles são até mesmo mais interessantes do que os de Burke" (O’Brien 1992: 615).

Depois de tudo o que foi dito, não parece, pois, que "Da força sempre atual do pensamento de Benjamin Constant e da necessidade de reconhecê-lo", seja um título inoportuno para apresentar este autor. 


\section{Referências Bibliográficas}

CONSTANT, Benjamin. Adolpho. Rio de Janeiro, Imago, 1992.

GAUCHET, Marcel. Benjamin Constant Écrits politiques. Paris, Gallimard,1997.

"Constant, Stäel et la Révolution française", in The French Revolution and the creation of modern political culture, vol. III The transformation of political culture 17891848 (org. por François Furet e Mona Ozouf). Londres/Paris, Pergamon Press, 1989.

MANENT, Pierre. História Intelectual do Liberalismo. Dez lições. Imago, Rio de Janeiro, 1990

O'BRIEN, Conor Cruise. The Great Melody. A Thematic Biography and Commented Anthology of Edmund Burke. Chicago University Press, 1992.

RAYNAUD, Philippe. "Préface" a CONSTANT: De la force du gouvernement actuel de la France et de la necessité de s'y rallier (1796). Des reactions politiques. Des effects de la Terreur (1797). Paris, Flammarion, 1988.

STAROBINSKI. "Benjamin Constant: comment parler quand l'éloquence est épuisée", in The French Revolution and the creation of modern political culture, vol. III The transformation of political culture 1789-1848 (org. por François Furet e Mona Ozouf). Londres/Paris, Pergamon Press, 1989.

TULARD, Jean et alii. Histoire et dictionnaire de la Révolution Française. Paris, Robert Laffont, 1987. 